http://jmscr.igmpublication.org/home/ ISSN (e)-2347-176x ISSN (p) 2455-0450

crossref DOI: https://dx.doi.org/10.18535/jmscr/v7i11.58

Journal Of Medical Science And Clinical Research

\title{
Evaluation of Serum Potassium Levels as Prognostic Marker in Acute Organophosphorus Poisoning in a Tertiary Care Centre
}

\author{
Authors \\ Dr Vandana Dandekar ${ }^{1}$, Dr Ashiti Jain ${ }^{2}$, Dr Aakash Barad ${ }^{3}$, Dr Jaishree Ghanekar ${ }^{4}$ \\ ${ }^{1}$ Assistant Prof, ${ }^{2}$ Junior Resident, ${ }^{3}$ Senior Resident, ${ }^{4}$ Prof \& Head, \\ Dept of Internal Medicine, MGM Medical College and Hospital, Navi Mumbai
}

\begin{abstract}
Background: It is apparent that although inhibition of cholinesterase plays an important role in organophosphate $(O P)$ toxicity, other factors are also important. One of the contributing factors for its severity is electrolyte imbalances esp. hypokalemia. This study was aimed at evaluating the levels of hypokalemia along with plasma cholinesterase (PChE) levels in predicting morbidity and mortality of acute OP poisoning in patients presenting in our hospital.

Methods: In this cross sectional study, patients with definitive diagnosis of OPC poisoning were enrolled. Pre-interventional history and clinical features were noted with severity assessment done according to Proudfoot classification, along with measurement of serum potassium $([K+])$ and PChE levels.

Results: Thirty OP poisoned patients $(22$ men, 8 women) were enrolled. A total of 30 cases who presented with clinical features of opc poisoning were classified according to Proud foot classification. Among them, $68.4 \%$ of cases (13 out of 17) developed hypokalemia. Muscle weakness and fasciculations developed with mean serum $[K+]$ levels of $2.90 \pm 0.11$. Ventilatory support was required at the mean serum [K+] levels of $\pm 0.10 \mathrm{mmol} / \mathrm{L}$. Mortality was noted when the mean serum $[\mathrm{K}+]$ reduced to $2.7 \pm 0.06 \mathrm{mmol} / \mathrm{L}$. Correlation of the ventilator support and mortality with serum $[K+]$ was significant $(P<0.001)$. Death was mostly observed among patients who had respiratory distress associated with hypokalemia and severly reduced PChE.

Conclusion: With severe clinical features of $O P$ poisoning, there was severe reduction in serum [K+] and $P C h E$ levels. Hence, these biochemical findings can be encouraged as predictive markers of severity of op poisoning. Clinicians and medical toxicologists should consider hypokalemia as an alarming sign of poor prognosis in OPC poisoned patients.

Keywords: Hypokalemia ; Organophosphate Poisoning; Prognosis.
\end{abstract}

\section{Introduction}

Organophosphate (OP) compounds are the most commonly consumed poison in India owing to their easy availability. Deliberate self-poisoning with pesticides, especially OP compounds, is an important public health problem worldwide which kills 200,000 people annually and its incidence keeps rising.
Table 1: Types of Organophosphorus Compounds

\begin{tabular}{|lc|}
\hline Dimethyl OP & $\begin{array}{c}\text { Diethyl OP } \\
\text { METHYL } \\
\text { PARATHION }\end{array}$ \\
\hline PARATHION & DICHLOROVOS \\
\hline DIAZINON & DIMETHOATE \\
\hline CHLOROPYRIFOS & MALATHION \\
\hline DICHLOROFENTHION & FENTHION \\
\hline COUMAPHOS &
\end{tabular}


OP compounds act by inhibiting the acetyl cholinesterase enzymes at muscarinic and nicotinic receptors, present in post synaptic membrane. As a result, erythrocyte cholinesterase and plasma cholinesterase (PChE) levels reduce in $\mathrm{OP}$ poisoning. It is apparent that although inhibition of cholinesterase plays a key role in the toxicity of OP compounds, individual susceptibility, inhibition of other enzymes and the direct effects of OPs on tissues are also important. One of the contributing factors for severity of OP poisoning is electrolyte imbalances. Hypokalemia is a frequent finding in Organophosphorus poisoning. In acute OP poisoning, the most common cause of mortality is respiratory arrest and acidosis as the result of respiratory muscle paralysis. Associated hypokalemia increases the muscle weakness. Hence, hypokalemia can be considered as an important cause for intensifying the poisoning.

Signs and symptoms of organophosphate poisoning

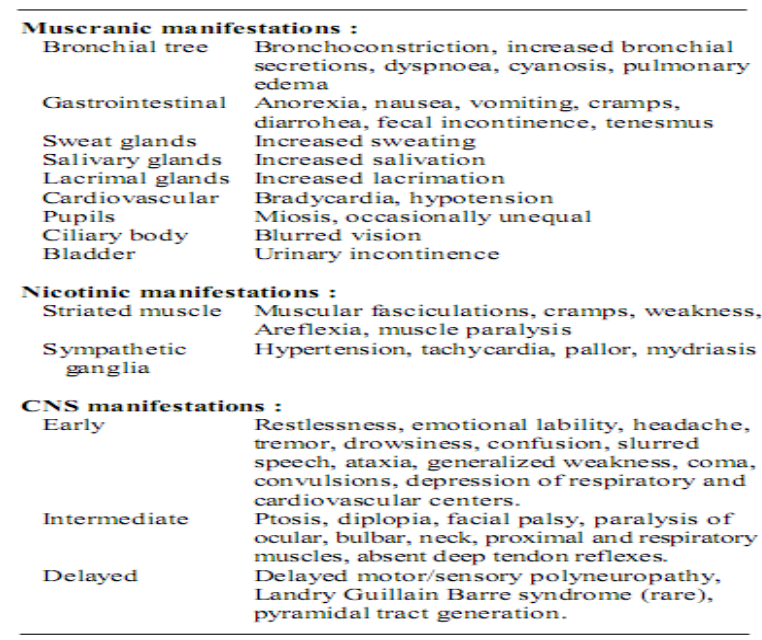

\section{Methodology}

The study was conducted at MGM medical college and hospital, navi mumbai, over a period of two years between January 2017 and October 2018. 30 patients presenting in the emergency room with alleged history of Organophosphorus poisoning and features of respiratory failure (requiring ventilatory support), who fulfilled the proposed inclusion and exclusion criteria were included in the study. Prior ethical approval for the study and the protocol was obtained from the institution ethics committee. After explaining the possible prognosis in the course of organophosphorus poisoning, consent from a responsible attendant / informant of the patient was obtained before the actual study was initiated. Inclusion Criteria for the study were as follows: Patients who had allegedly consumed organophosphate poison and admitted to hospital within 24 hour of ingestion, irrespective of age / sex.

Exclusion Criteria for the study were as follows:

1. Patients with dual insecticide / multiple poisoning with other drugs such as opioids, diazepam, barbiturate etc.,

2. Patients with history of respiratory diseases including bronchial asthma, cardiac diseases, neuromuscular diseases like myasthenia gravis or muscular dystrophy or other concomitant illnesses.

3. All conditions causing of hypokalemiaalkalosis, diuretic use, beta agonist use, high aldosterone levels, insulin overdose, laxative abuse, corticosteroids,

Each of the patients with Organophosphorus poisoning were assessed clinically with detailed history and thorough physical examination.

Features correlating to: (a) Severity of organophosphorus poisoning and (b) Respiratory failure requiring mechanical ventilation was assessed.

(a) Criteria for grading of severity of organophosphorus poisoning:

- The grading of clinical severity of organophosphate poisoning

\begin{tabular}{|c|c|c|}
\hline Grade & Symptoms & Signs \\
\hline Mild & $\begin{array}{l}\text { Dizziness, anxiety, } \\
\text { headache, tightness } \\
\text { of breath }\end{array}$ & $\begin{array}{l}\text { Rhinorrhea, sweating, } \\
\text { salivation, nausea, } \\
\text { weakness, coughing, } \\
\text { lacrimation, mild bradycardia } \\
\text { and hypotension }\end{array}$ \\
\hline Moderate & $\begin{array}{l}\text { Restlessness, } \\
\text { confusion, dyspnea, } \\
\text { disorientation, } \\
\text { abdominal pain, } \\
\text { vomiting, diarrhea, } \\
\text { drowsiness }\end{array}$ & $\begin{array}{l}\text { Pallor, miosis/mydriasis, } \\
\text { bradycardia/ } \\
\text { tachycardia, hypotension/ } \\
\text { hypertension, } \\
\text { muscle twitching, } \\
\text { fasciculation, respiratory } \\
\text { depression, bronchoorrhea, } \\
\text { bronchospasm, } \\
\text { loss of consciousness }\end{array}$ \\
\hline Severe & & $\begin{array}{l}\text { Convulsions, respiratory } \\
\text { failure, pulmonary edema, } \\
\text { flaccid paralysis, involuntary } \\
\text { micturation/defecation } \\
\text { cyanosis, deep coma }\end{array}$ \\
\hline Fatal & & $\begin{array}{l}\text { Coma, convulsions, } \\
\text { hypersecretions and apnea } \\
\text { within a few minute after } \\
\text { exposure }\end{array}$ \\
\hline
\end{tabular}


- Based on various factor which influence on ventilator support the severity of organophosphate poison was classified in mild, moderate and severe.

\begin{tabular}{|l|c|c|c|}
\hline $\begin{array}{l}\text { Grades of } \\
\text { poisoning }\end{array}$ & $\begin{array}{c}\text { Level of } \\
\text { consciousness }\end{array}$ & Pupil size & $\begin{array}{c}\text { Fasciculatio } \\
\text { n score }\end{array}$ \\
\hline Mild & $\begin{array}{c}\text { Normal } \\
\text { GCS 12-15 }\end{array}$ & $\geq 4 \mathrm{~mm}$. & $0-1$. \\
\hline Moderate & $\begin{array}{c}\text { slightly decreased. } \\
\text { GCS 8-11 }\end{array}$ & $2-3 \mathrm{~mm}$. & $2-4$. \\
\hline Severe & $\begin{array}{c}\text { Coma } \\
\text { GCS }<7, \\
\text { history of } \\
\text { convulsion }\end{array}$ & $<1 \mathrm{~mm}$. & $>5$, \\
\hline
\end{tabular}

Fasciculation grading was done by giving 1 for each fasciculation to the anterior chest, back of chest, anterior and posterior side of abdomen, right and left arm, right and left leg. Total sum of this is called fasciculation score

(a) Criteria for diagnosis of respiratory failure: The patients who have features suggestive of severe poisoning as stated above are then assessed for ventilatory support based on following:

- Apnoea

- Obvious Hypoventilation

- Persistent Cyanosis inspite of 02 supplementation

- Persistent Tachypnoea - Respiratory rate (per minute) $>24$

- Persistent Sp02 < $90 \%$ with Oxygen supplementation by non invasive means.

- Active use of accessory muscles of respiration.

Immediately after clinical assessment, blood samples were withdrawn and sent for investigations including Haemoglobin level, Total and Differential Blood Count (DC), serum electrolytes and Serum Cholinesterase levels, arterial blood gas analysis. (More investigations as necessary were done after institution of treatment and ventilation).

Immediate Management: Patients were given gastric wash, body wash and intravenous cannulation done. Injection Pralidoxime, bolus dose -2 gm. I.V. and Inj. Atropine bolus 5-10 mg. IV every 5 mins were given till signs of atropinisation was achieved. Patients were reassessed for respiratory failure, and if so, intubated and shifted to Medical Intensive Care unit by Ambu ventilation. On arrival in the Medical Intensive Care Unit, the patients were immediately connected to ventilator and supportive therapy was initiated along with definitive therapy.

The Definitive Therapy for Organophosphorus poisoning: Protocol followed was:- $20 \%$ of total atropine required for atropinisation as Inj Atropine Infusion with $1 \mathrm{mg}$ bolus IV when required, till signs of atropiniiation were achieved - Inj PAM infusion at $50-100 \mathrm{mg} / \mathrm{hr}$ administered for the initial $48 \mathrm{hrs}$. depending upon the severity.( following the initial bolus $2 \mathrm{gm}$. given on arrival at emergency ward ).

\section{Supportive Therapy (as required):}

Maintenance of intravascular volume by IV fluids.

Antibiotics to prevent and treat infections. Inotropic support for cardiac functions. a Regular and thorough endotracheal and oral suction. Chest and limb physiotherapy. - Nutritional support by enteral feeding when indicated. Measures to reduce gastric acidity and secretions.

Ventilator Management: The patients were put on Drager Savina ventilator with the following initial settings-Mode - CMV with pressure support Tidal volume $-8-10 \mathrm{ml} / \mathrm{kg}$ body wt, Respiratory rate - 10-12 bpm, Fi02 -0.4-0.6, PEEP - 2 to $5 \mathrm{~cm}$ $\mathrm{H} 2 \mathrm{O}$. Increments were used as indicated. Weaning Technique consisted of SIMV with PS - CPAP TPiece

Investigations: Repeat and / or additional investigations as required by the patient's status were ordered.

Serumcholinesterase: The reference values and Interpretations / definitions are as follows:

The serum cholinesterase activity was measured by kinetic/ DGKC calorimetric method, of Zydus Pathline Limited. EDTA samples were sent to the laboratory. The results are expressed in $\mathrm{KU} / \mathrm{L}$ which is $\mathrm{U} / \mathrm{L} \times 1000$. The laboratory reference range used in the present study for serum cholinesterase: 5100 to 11700 IU / Ltr. Based on the Serum Cholinesterase values, the severity of 
poisoning may be defined as per (Proudfoot classification) with above normal range:

- Mild poisoning: SCE. level $20-50 \%$ of normal / $>2001 \mathrm{IU} / \mathrm{L}$

- Moderate poisoning: SCE. level $10-20 \%$ of normal /1001-2000 IU / L

- Severe poisoning: $\quad$ SCE. level $<10 \quad \%$ of normal $/<$ $1000 \mathrm{IU} / \mathrm{L}$

\section{Statistical Analysis}

All the collected data was entered in Microsoft Excel sheet and then transferred to Statistical Package of Social Sciences (SPSS Inc., Chicago, IL, USA) software ver. 17 for analysis. Data are presented with median or mean and standard deviation (SD) for continuous variables and frequency and percentage for categorical variables and analysed using chi-square test. One-way ANOVA test was used to compare the means of serum $[\mathrm{K}+]$ between different clinical features. Pvalue $<0.05$ was taken as level of significance.

\section{Results}

In the study, Hypokalemia was observed in $63.3 \%$ of OPC poisoning cases.

Table no 1 Incidence of Hypokalemia

\begin{tabular}{|l|c|c|}
\hline Hypokalemia & Frequency & Percent \\
\hline Absent & 11 & 36.7 \\
\hline Present & 19 & 63.3 \\
\hline Total & 30 & 100.0 \\
\hline
\end{tabular}

Table no 2 Type of OPC compound vs Hypokalemia

\begin{tabular}{|c|c|c|c|c|c|}
\hline & & & \multicolumn{2}{|c|}{ Hypokalemia } & \multirow[b]{2}{*}{ Total } \\
\hline & & & No & Yes & \\
\hline \multirow{10}{*}{$\begin{array}{l}\text { type of OPC } \\
\text { compound }\end{array}$} & \multirow[t]{2}{*}{ Dichlorphos } & Count & 1 & 0 & 1 \\
\hline & & $\%$ & $9.1 \%$ & $0.0 \%$ & $3.3 \%$ \\
\hline & \multirow[t]{2}{*}{ Dimethoate } & Count & 1 & 1 & 2 \\
\hline & & $\%$ & $9.1 \%$ & $5.3 \%$ & $6.7 \%$ \\
\hline & \multirow[t]{2}{*}{ Parathion } & Count & 0 & 1 & 1 \\
\hline & & $\%$ & $0.0 \%$ & $5.3 \%$ & $3.3 \%$ \\
\hline & \multirow[t]{2}{*}{ Phorate } & Count & 8 & 13 & 21 \\
\hline & & $\%$ & $72.7 \%$ & $68.4 \%$ & $70.0 \%$ \\
\hline & \multirow[t]{2}{*}{ Unknown } & Count & 1 & 4 & 5 \\
\hline & & $\%$ & $9.1 \%$ & $21.1 \%$ & $16.7 \%$ \\
\hline \multirow{2}{*}{\multicolumn{2}{|c|}{ Total }} & Count & 11 & 19 & 30 \\
\hline & & $\%$ & $100.0 \%$ & $100.0 \%$ & $100.0 \%$ \\
\hline
\end{tabular}

As seen in the above table, hypokalemia was observed most commonly in phorate OPC (5.3\% and dimethoate $(5.3 \%)$ though the poisoning cases $(68.4 \%)$ followed by parathion difference was statistically insignificant.

Table no 3 Convulsion vs Hypokalemia

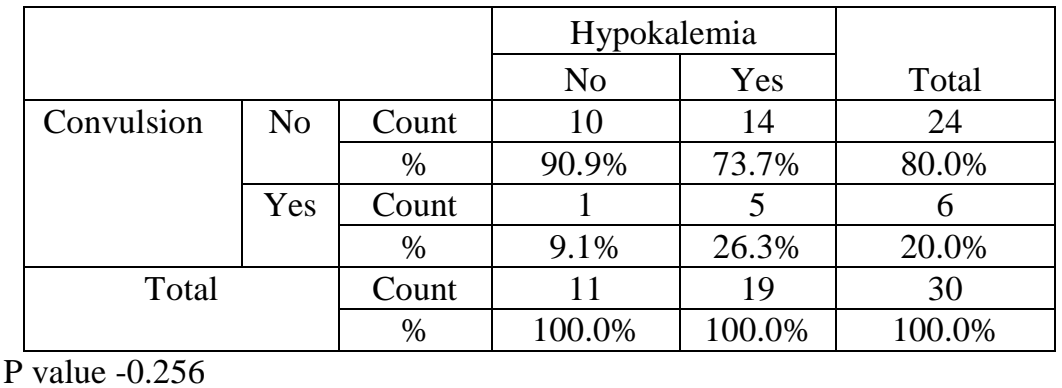

As seen in the above table, Convulsion was observed in $26.3 \%$ of Hypokalemic OPC poisoning cases as compared to $9.1 \%$ of normokalemic OPC poisoning cases and the difference was statistically insignificant. 
Table no 4 Respiratory Distress RR> 24 vs Hypokalemia

\begin{tabular}{|c|c|c|c|c|c|}
\hline & \multicolumn{2}{|c|}{ Hypokalemia } & \multirow[b]{2}{*}{ Total } \\
\hline & & & No & Yes & \\
\hline \multirow{4}{*}{$\begin{array}{l}\text { Respiratory } \\
\text { Distress RR> } \\
24\end{array}$} & \multirow{2}{*}{ No } & Count & 8 & 9 & 17 \\
\hline & & $\%$ & $72.7 \%$ & $47.4 \%$ & $56.7 \%$ \\
\hline & \multirow[t]{2}{*}{ Yes } & Count & 3 & 10 & 13 \\
\hline & & $\%$ & $27.3 \%$ & $52.6 \%$ & $43.3 \%$ \\
\hline \multirow{2}{*}{\multicolumn{2}{|c|}{ Total }} & Count & 11 & 19 & 30 \\
\hline & & $\%$ & $100.0 \%$ & $100.0 \%$ & $100.0 \%$ \\
\hline
\end{tabular}

As seen in the above table, Respiratory distress normokalemic OPC poisoning cases and the $(\mathrm{RR}>24)$ was observed in $52.6 \%$ of Hypokalemic difference was statistically insignificant. OPC poisoning cases as compared to $27.3 \%$ of

Table no 5 Requirement of ventilator vs Hypokalemia

\begin{tabular}{|c|c|c|c|c|c|}
\hline \multicolumn{2}{|c|}{} & \multicolumn{2}{|c|}{ Hypokalemia } & \multirow{2}{*}{} \\
\cline { 3 - 5 } \multicolumn{2}{c|}{} & No & Yes & Total \\
\hline \multirow{2}{*}{$\begin{array}{l}\text { Requirement } \\
\text { of ventilator }\end{array}$} & \multirow{2}{*}{ No } & Count & 10 & 10 & 20 \\
\cline { 3 - 6 } & & $\%$ & $90.9 \%$ & $52.6 \%$ & $66.7 \%$ \\
\cline { 3 - 6 } & \multirow{2}{*}{ Yes } & Count & 1 & 9 & 10 \\
\cline { 3 - 6 } & & $\%$ & $9.1 \%$ & $47.4 \%$ & $33.3 \%$ \\
\hline \multirow{2}{*}{ Total } & Count & 11 & 19 & 30 \\
\cline { 3 - 6 } & $\%$ & $100.0 \%$ & $100.0 \%$ & $100.0 \%$ \\
\hline
\end{tabular}

As seen in the above table, ventilator requirement normokalemic OPC poisoning cases and the was observed in $47.4 \%$ of Hypokalemic OPC difference was statistically significant. poisoning cases as compared to $9.1 \%$ of

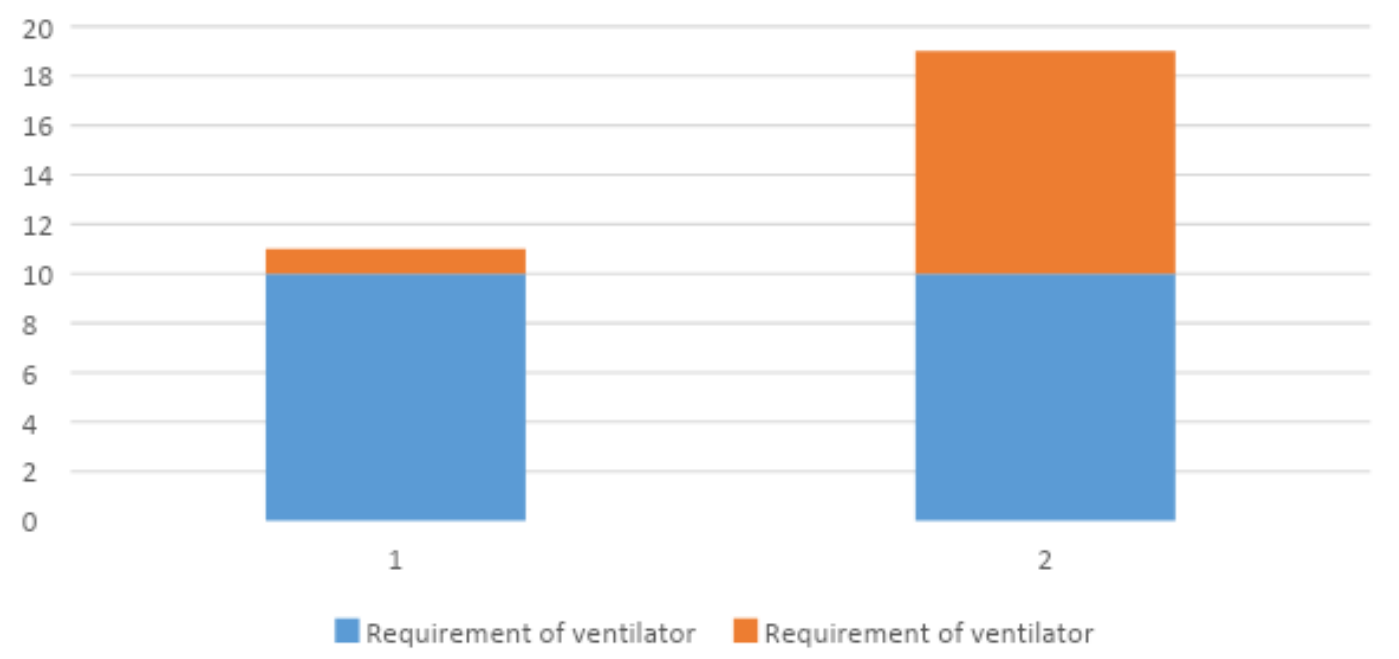

Table no 6 Apache Score vs Hypokalemia

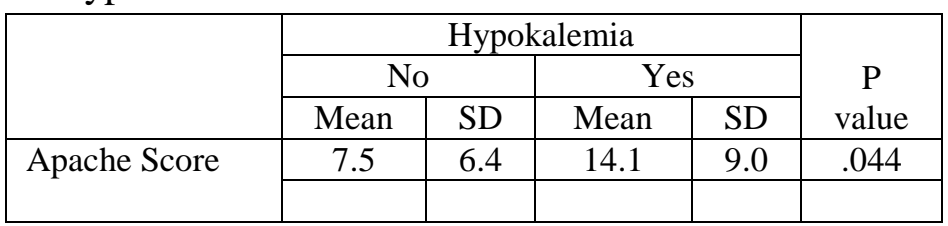

As seen in the above table, mean Apache Score was significantly higher in hypokalemic OPC poisoning cases as compared to normokalemic OPC poisoning cases. 
Table no 7 Mortality vs Hypokalemia

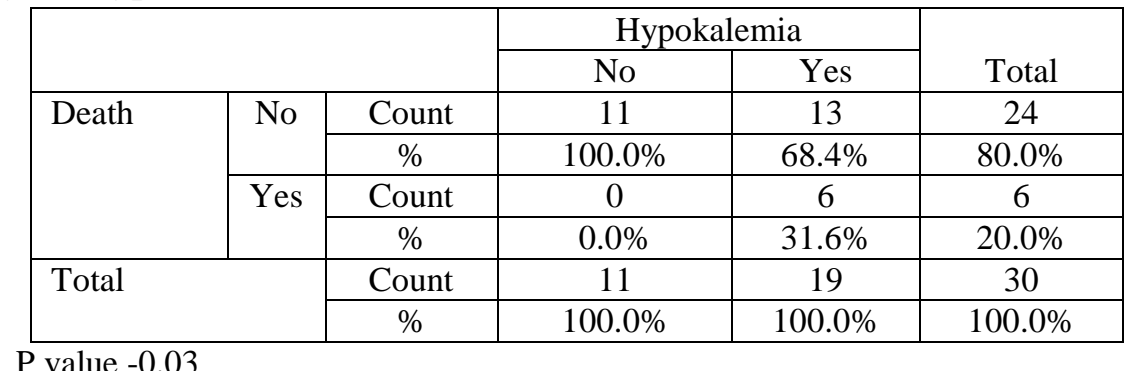

As seen in the above table, death was observed in cases and the difference was statistically $31.6 \%$ of Hypokalemic OPC poisoning cases as significant. compared to $0 \%$ of normokalemic OPC poisoning

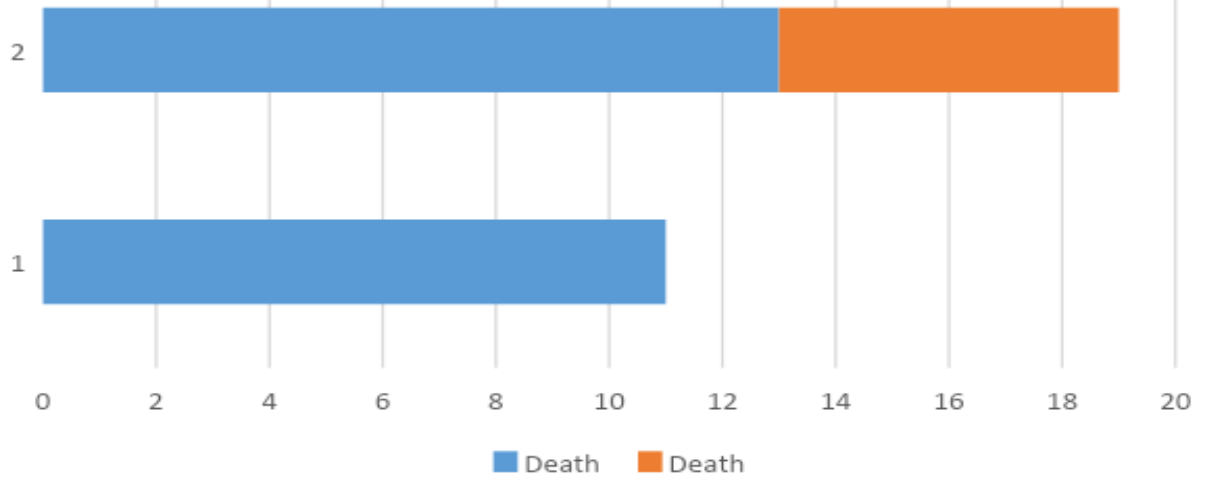

Table no 8 Duration of hospital stay vs Hypokalemia

\begin{tabular}{|l|l|c|c|c|c|}
\hline \multicolumn{2}{|c|}{} & \multicolumn{2}{|c|}{ Hypokalemia } & \multirow{2}{*}{ Total } \\
\cline { 3 - 6 } \multirow{2}{*}{$\begin{array}{l}\text { Duration of } \\
\text { hospital stay }\end{array}$} & less than 10 days & Count & 9 & 13 & 22 \\
\cline { 3 - 6 } & & $\%$ & $81.8 \%$ & $68.4 \%$ & $73.3 \%$ \\
\cline { 3 - 6 } & more than 10 days & Count & 2 & 6 & 8 \\
\cline { 3 - 6 } & & $\%$ & $18.2 \%$ & $31.6 \%$ & $26.7 \%$ \\
\hline Total & Count & 11 & 19 & 30 \\
\cline { 3 - 6 } & $\%$ & $100.0 \%$ & $100.0 \%$ & $100.0 \%$ \\
\hline
\end{tabular}

As seen in the above table, more than 10 days was observed in $31.6 \%$ of Hypokalemic OPC poisoning cases as compared to $18.2 \%$ of normokalemic OPC poisoning cases and the difference was statistically insignificant.

\section{Discussion}

In the present study, there was male predominance (73.3\%) as compared to female (26.7\%). Similarly in the study conducted by Tanveer Hassan Banday et al., the female to male ratio is 1:3.2. The incidence of poisoning was higher in males than in females $(76.6 \%$ Vs. $23.3 \%) .{ }^{1}$ Similar trend was also observed by Safdar et al., and Aziza et $a l .^{2,3}$ However, the female to male ratio given by Ather et al., is 1:1 and Tall et al., is 1:1.8 which is quite different from present study. 4,5

In the present study, Hypokalemia was observed in $63.3 \%$ of OPC poisoning cases. Similarly in the study conducted by Tanveer Hassan Banday et al., hypokalemia were found in $15.03 \%$ of cases respectively. ${ }^{1}$

In the present study, phorate $(70 \%)$ was the most common type of OPC poisoning followed by dimethoate $(6.7 \%)$, dichlorphos $(3.3 \%)$ and parathion $(3.3 \%)$ 
In the present study, mean Apache Score was significantly higher in hypokalemic OPC poisoning cases as compared to normokalemic OPC poisoning cases.

In the present study, hypokalemia was observed most commonly in phorate OPC poisoning cases $(68.4 \%)$ followed by parathion $(5.3 \%$ and dimethoate $(5.3 \%)$ though the difference was statistically insignificant.

In the present study, hypokalemia was observed most commonly in severe grade of OPC poisoning cases $(42.2 \%)$ followed by moderate grade $(36.8 \%)$ and mild $(21.1 \%)$ though the difference was statistically insignificant. Similarly in the study by Syed M Ahmed et al., out of 86 patients, $14(16.3 \%)$ had mild, 30 (34.9\%) had moderate and $42(48.8 \%)$ had severe grade of poisoning. In the present study, Respiratory distress (RR> 24) was observed in $52.6 \%$ of Hypokalemic OPC poisoning cases as compared to $27.3 \%$ of normokalemic OPC poisoning cases and the difference was statistically insignificant. ${ }^{6}$

Ventilatorrequirementwas observed in $47.4 \%$ of Hypokalemic OPC poisoning cases as compared to $9.1 \%$ of normokalemic OPC poisoning cases and the difference was statistically significant. This findings is in agreement with the study conducted by Banday, et al., in which Ventilator requirement was observed in $39.8 \%$ of OPC cases. ${ }^{1}$ This findings is in agreement with the study conducted by Mahadeshwara Prasad et al in which both respiratory distress and mechanical ventilation taken together and statistically significant $(\mathrm{p}$ value $<0.001){ }^{7}$

In the present study, hypokalemia was observed most commonly in severe proud foot grade of OPC poisoning cases $(68.4 \%)$ followed by mild $(26.3 \%)$ and moderate grade $(5.3 \%)$ though the difference was statistically insignificant.

In the present study, Convulsion and Fasciculation was observed in $26.3 \%$ and $15.8 \%$ of Hypokalemic OPC poisoning cases and the difference was statistically insignificant. This findings is in agreement with the study conducted by Indranil Banerjee et al., Fasciculation was observed in $10 \%$ of OPC poisoning cases. ${ }^{8}$

In the present study, death was observed in $31.6 \%$ of Hypokalemic OPC poisoning cases as compared to $0 \%$ of normokalemic OPC poisoning cases and the difference was statistically significant. In D.R. Mahadeshwara Prasad et al study, death occurred in patients with a mean potassium levels of $2.90+/-0.057 \mathrm{meq} / \mathrm{dl}$ (p value $<$ 0.001). In Lyzhnikov EA et al study, severe arrhythmia and cardiac arrest leading to death occurred in 29 patients who are found to have hypernatremia and hypokalemia. ${ }^{7,9}$

In the present study, more than 10 days was observed in $31.6 \%$ of Hypokalemic OPC poisoning cases as compared to $18.2 \%$ of normokalemic OPC poisoning cases and the difference was statistically insignificant.

\section{Conclusion}

The ease of access to OPCs in developing countries like India has made this compound the main tool for suicidal poisoning. Present study was conducted keeping in mind the paucity of studies for OPC-Poisoning and the relation of electrolyte derangements with it. From the study conducted, it was found that Hypokalemia increases both morbidity and mortality in organophosphorus compound poisoning significantly. Hence Hypokalemia can be used as a reliable and a cost effective marker of morbidity and mortality in organophosphorus compound poisoning. Early hospitalization and correction of hypokalemia can be life saving in OPC-Poisoning.

Funding: No funding sources

Conflict of interest: None

Ethical approval: The study was approved by the institutional ethics committee.

\section{References}

1. Banday TH, Tathineni B, Desai MS, Naik $\mathrm{V}$. Predictors of morbidity and mortality in organophosphorus poisoning: A case study 
in rural hospital in Karnataka, India. North Am J Med Sci 2015;7:259-65

2. Safdar A, Saeed A, Muhammad NR. Organophosphorus poisoning: Emergency management in intensive care unit. Prof 2003;10:308-14.

3. Hussain AM, Sultan ST. Organophosphorus insecticide poisoning: Management in surgical intensive care unit. J Coll Physicians Surg Pak 2005; 15:100-2.

4. Ather NA, Ara J, Khan EA, Sattar RA, Durrani R. Acute organophosphate insecticide poisoning. J Surg Pak 2008;13:71-4.

5. Tall A, Ly AB, Nabeth P, Sall AA, Sarr FD, Faye $J$, et al. Epidemiological investigation of death cases by pesticide poisoning. J Agric Biotechnol Sustainable Develop 2010;2:51-5.

6. Syed M Ahmed et al., Survival pattern in patients with acute organophosphate poisoning on mechanical ventilation: A retrospective intensive care unit-based study in a tertiary care teaching hospital, Indian J Anaesth. 2014 Jan-Feb; 58(1): $11-17$

7. Mahadeshwara Prasad D.R et al., A Study of Acute Organophosphate Poisoning at a Tertiary Hospital, Belgaum, Karnataka, Medico legal Update,2012; Volume 12 (2):75-79

8. Indranil Banerjee et al., ClinicoEpidemiological Characteristics of Patients Presenting with Organophosphorus Poisoning, N Am J Med Sci. 2012 Mar; 4(3): 147-150.

9. Lyzhnikov EA, Savina AS, Shepelev VM.Kardiologiia.1975 Sep;15(9):126-9. 